\title{
Protection measures implemented by New Zealand for vulnerable marine ecosystems in the South Pacific Ocean
}

\author{
Andrew J. Penney ${ }^{1, *}$, Steven J. Parker ${ }^{2}$, James H. Brown ${ }^{1}$ \\ ${ }^{1}$ Ministry of Fisheries, PO Box 1020, Wellington, New Zealand \\ ${ }^{2}$ National Institute of Water and Atmospheric Research, PO Box 893 Nelson, New Zealand
}

\begin{abstract}
Interim measures for bottom fisheries adopted by the South Pacific Regional Fisheries Management Organization (SPRFMO) require participants to limit bottom fishing to currently fished areas and prevent significant adverse impacts on vulnerable marine ecosystems (VMEs). The New Zealand bottom trawl footprint consists of two hundred 20 min latitude $\times 20$ min longitude blocks trawled over the period 2002-2006 within which New Zealand flagged vessels reported 11425 tows, primarily targeting orange roughy Hoplostethus atlanticus. Past effort and seabed impact levels differ substantially between these blocks, ranging from lightly $\left(<3\right.$ tows block $\left.{ }^{-1}\right)$ to heavily trawled $\left(>50\right.$ tows block ${ }^{-1}$ ), with a maximum of 1417 tows in the most heavily trawled block. Effort data were used to stratify the bottom trawl footprint into 3 effort tiers as the basis for a management approach tailored to levels of past impact: (1) adequate and representative spatial closure of areas likely to support VMEs, with emphasis on less impacted areas; (2) a move-on rule in areas where likelihood of encounter with a VME is unknown; and (3) constraining fishing effort to remaining open areas most impacted by past fishing. Sixty-two lightly trawled blocks were closed to prevent impact in these areas; 69 moderately trawled blocks were subjected to a move-on rule; and 69 heavily trawled blocks were designated as open to fishing. A further 20 blocks were closed to provide representative protection within the moderately and heavily trawled tiers. In the absence of seabed biodiversity data, biologically important physical factors, primarily depth range and topography, were used to select interim precautionary closures and to evaluate representativity of closed in comparison with open areas. Geospatial analyses are presented on the distribution and representivity of seabed depth within open, move-on and closed blocks in each fishing area in comparison with the overall SPRFMO Area.
\end{abstract}

KEY WORDS: Vulnerable marine ecosystems · Deep-sea coral $\cdot$ Trawling impacts $\cdot$ Spatial fisheries management $\cdot$ SPRFMO

\section{INTRODUCTION}

New Zealand is closely surrounded by extensive volcanic underwater topographic features ranging from the $10000 \mathrm{~m}$ deep Kermadec Trench in the north to the $4000 \mathrm{~m}$ high Macquarie Ridge in the South, and from the Lord Howe Rise and Challenger Plateau in the west to the Louisville Seamount chain in the east. The Food and Agriculture Organization of the United Nations (FAO) lists such features, particularly submerged edges and slopes; summits and flanks of seamounts, guyots, banks, knolls and hills; canyons, trenches and hydrothermal vents as features that potentially support species, groups or communities which are 'considered sensitive and potentially vulnerable to deep sea fisheries in the high seas, and which may contribute to forming vulnerable marine ecosystems (VMEs)' (FAO 2008, p. 16).

UN General Assembly Resolution 61/105 (UNGA 2006) requires that such areas on the high seas should be closed to bottom fisheries unless adequate management measures have been put in place to prevent 
significant adverse impacts on VMEs. Participants negotiating the South Pacific Regional Fisheries Management Organisation (SPRFMO) accordingly adopted interim measures for high seas bottom fisheries in 2007 (SPRFMO 2007a) ${ }^{\mathbf{1}}$, including limiting bottom fishing to areas where such fishing is currently occurring and, in areas where VMEs are known or likely to occur, implementing measures 'to prevent significant adverse impacts on vulnerable marine ecosystems and the longterm sustainability of deep sea fish stocks' (SPRFMO 2007a, Bottom Fisheries Interim Measure 3). Vessels encountering evidence of VMEs are required to implement a move-on rule and cease fishing operations within 5 nautical miles (n miles) of that site. New Zealand is implementing these measures through a series of sequential steps. Some of these requirements were already satisfied by existing management systems for New Zealand fisheries (e.g. vessel monitoring systems, VMS), while others have required enhancement of existing systems (e.g. increased observer coverage). Requirements to limit bottom fishery impacts to currently fished areas, and to prevent significant adverse impacts in these areas, are being implemented using a combination of precautionary closures, open areas and areas where the SPRFMO move-on rule is implemented.

New Zealand's implementation of the SPRFMO interim measures began with full observer coverage for bottom trawling in 2007, followed by conservation and management measures that came into effect in May 2008 for the 2008 high seas bottom trawling season, implemented as conditions on the high seas fishing permits required by New Zealand flagged vessels fishing the high seas. Here we describe the process whereby these measures were developed, present the information used to design these measures and evaluate the representativity of closed and move-on areas, in terms of biologically important physical factors, in comparison with areas left open to fishing. There is an emerging literature on the design of effective deep-water closures for the representative protection of deep-sea biodiversity (e.g. Davies et al. 2008, Rogers et al. 2008, Abdulla et al. 2009, Clark \& Rowden 2009, Williams et al. 2009), and we explain to what extent the guiding principles emanating from this work have been applied to the design of interim protection measures, and what further information or work is required for these principles to be more rigorously applied in the design of future longterm spatial protection measures.

\footnotetext{
${ }^{1}$ The SPRFMO Area is under negotiation, but for the purposes of the interim measures and the present study it is the high seas area south of the Equator, north of the CCAMLR Convention area, east of the SIOFA Convention Area and west of the areas of fisheries jurisdictions of South American States.
}

\section{MAPPING THE NEW ZEALAND BOTTOM TRAWL FOOTPRINT}

In terms of the Benthic Assessment Framework adopted by SPRFMO in 2007, currently fished areas are defined as the bottom fishing 'footprint', consisting of 20 min latitude $\times 20$ min longitude blocks within which at least 1 trawl occurred over 2002-2006 (SPRFMO 2007b). The New Zealand high seas bottom trawling footprint was mapped using catch and effort data reported to the New Zealand Ministry of Fisheries on compulsory catch and effort returns which report all trawl tow start and end positions in latitude/longitude to the nearest minute. The resultant bottom trawl footprint consists of two hundred 20 min latitude $\times 20 \mathrm{~min}$ longitude blocks comprising 5 distinct fishing areas: Lord Howe Rise, Challenger Plateau, West Norfolk Ridge, Three Kings Ridge and Louisville Ridge (Fig. 1).

From 2002 to 2006, 11145 bottom trawls were reported by New Zealand vessels in these fishing areas and levels of past fishing effort differed substantially between individual $20 \times 20$ min trawl footprint blocks. A total of 62 blocks were classified as lightly trawled, with a combined total of 92 tows at $<3$ tows per block and an effective average of zero tows per year. At the other end of the scale, half the remaining blocks (69 blocks) had 10533 tows, with $>50$ tows (average 10 tows $\mathrm{yr}^{-1}$ ) per block and a maximum total of 1417 tows reported over 2002-2006 in the most heavily trawled block (on the Challenger Plateau). Within this area, comprising a heavily trawled one-third of the total footprint, $95 \%$ of the trawling effort occurred, 97\% (8957 tonnes [t]) of the New Zealand high seas orange roughy Hoplostethus atlanticus catch was made, much of the trawling was conducted on shallower features and seabed impacts will have been most concentrated (MFish 2008). Between these effort extremes, the remaining one-third of the footprint ( 69 blocks) had $5 \%$ of the effort (559 tows) and 3\% (265 t) of the orange roughy catch. Within these moderately trawled blocks, most trawls were conducted on flatter areas adjacent to shallower features, and seabed impacts would have been relatively low.

\section{PREVENTION OF SIGNIFICANT ADVERSE IMPACTS ON VMES}

In terms of the SPRFMO interim measures for bottom fisheries, participants are required to close areas where VMEs are 'known or likely to occur', unless adequate management measures have been implemented to prevent 'significant adverse impacts' on VMEs in such areas. Significant adverse impacts remain undefined but, following UNGA Resolution 61/105 (UNGA 

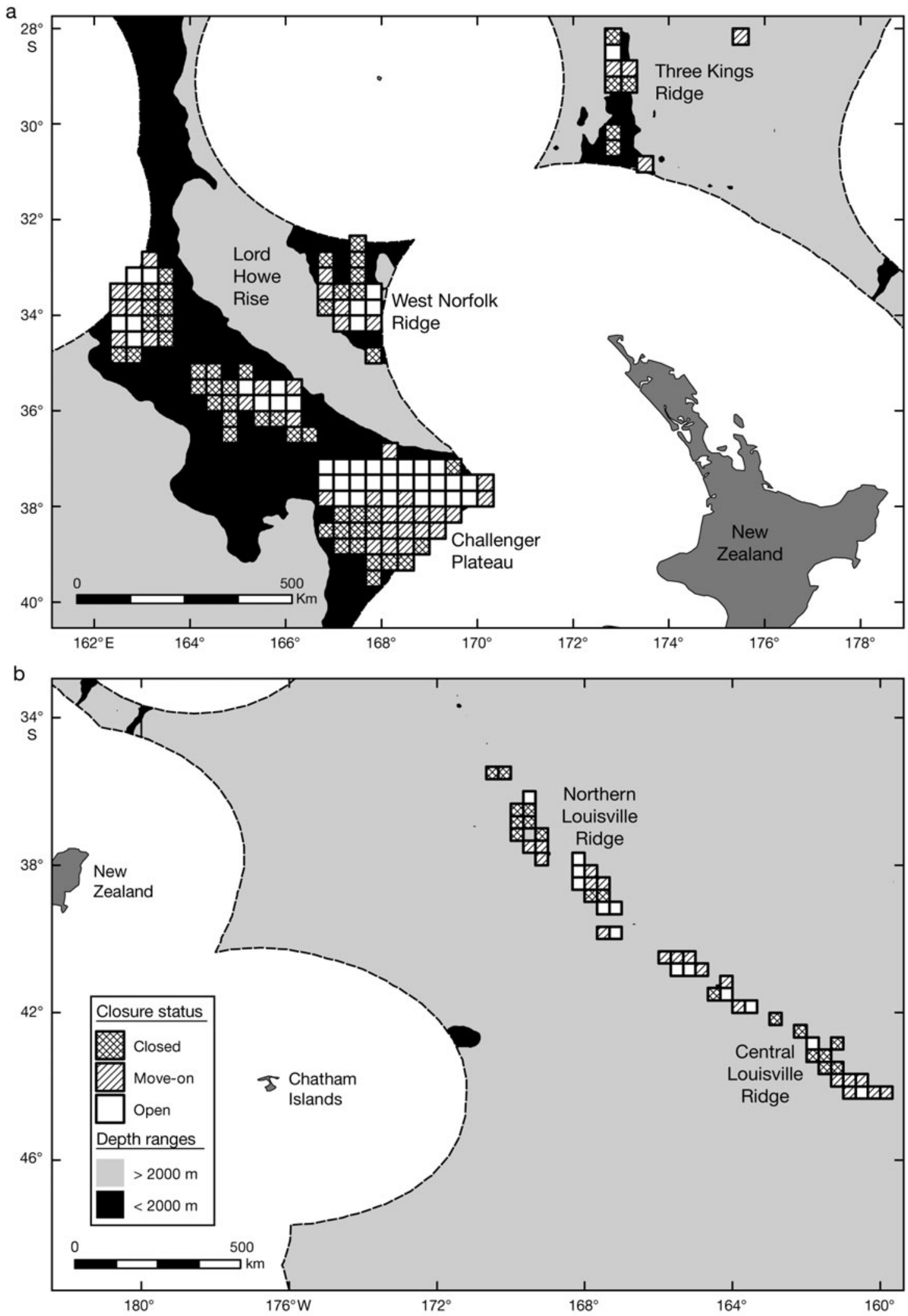

Fig. 1. Geographic distribution of open, move-on and closed New Zealand bottom trawl footprint blocks in (a) the Lord Howe Rise, Challenger Plateau, West Norfolk Ridge and Three Kings Ridge fishing areas; and (b) the Northern and Central Louisville Ridge areas (southern Louisville footprint blocks not shown). Dark grey shading shows the trawlable seabed area $<2000 \mathrm{~m}$ depth 
2007), concerns focus on impacts on underwater topographic features which support VMEs, particularly seamounts and biogenic habitat-forming cold-water corals and sponge fields. In areas where presence of VMEs is unknown, participants are required to implement the $5 \mathrm{n}$ mile move-on rule. The specific definition of 'evidence of a VME' developed by New Zealand to trigger this move-on rule is described in detail by Parker et al. (2009, this Theme Section).

Specific management and mitigation measures to meet the requirements of these interim measures were developed in consultation with industry, environmental non-governmental organizations and government departments concerned with environmental conservation. Expectedly, competing objectives or requirements were expressed by participants in these consultations: (1) to protect all features known or likely to support vulnerable marine species from any significant adverse impacts from bottom fishing operations; and (2) to provide access to adequate and suitable target areas to provide for a viable and sustainable deep-water trawl fishery.

The management approach has taken attempts to balance these competing objectives. Recognising the difficulty of defining 'significant adverse impacts', New Zealand has implemented measures which instead attempt to provide for 'adequate and representative protection' from trawling impacts. While this requires functional definitions of 'adequate' and 'representative' to be adopted, there has recently been substantial international development of approaches, guidelines and best practice in defining these concepts as they pertain to designing spatial protection measures for marine ecosystems (see Davies et al. 2008, Rogers et al. 2008, Abdulla et al. 2009, Clark \& Rowden 2009, Williams et al. 2009). An approach based on implementing spatial protection measures representative of the bio- and geodiversity of the area also inevitably requires that such measures need to be designed and implemented at an ecosystem, biotype or biome level (sensu Williams et al. 2009), and not at an individual feature or organism level.

\section{Three-tier management approach}

The combination of the 3 competing requirements to close or adequately protect areas known or likely to contain VMEs, to implement a move-on rule in areas where likelihood of encounters with evidence of a VME is unknown and to provide for suitable target areas for a viable and sustainable deep-water trawl fishery essentially dictates a 3-tiered approach to im- plementation of management measures. New Zealand's approach has been to specifically tailor management measures to incorporate known or likely bio- and geodiversity of the fished areas, as well as levels of past effort and impact. The 3-tier effort stratification of the New Zealand bottom trawl footprint intentionally facilitates such an approach.

New Zealand's 3-tiered approach to implementing VME protection measures has been designed to provide: (1) adequate and representative spatial closure of areas likely to support VMEs, with emphasis on protecting areas less impacted by past fishing effort; (2) implementation of the SPRFMO move-on rule in areas where likelihood of encounter with evidence of a VME is unknown; and (3) constraining future fishing effort to the remaining open areas which have already been most impacted by past fishing. An overview of the key characteristics of the 3 effort tiers and the management measures implemented within each tier is shown in Fig. 2; a summary of the total number of blocks and numbers closed within each fishing area is shown in Table 1. The geographic distribution of the New Zealand bottom trawl footprint blocks, indicating closure status of each block, is shown in Fig. 1 for Lord Howe Rise, Challenger Plateau, West Norfolk Ridge, Three Kings Ridge and the Northern and Central Louisville Ridge areas.

\begin{tabular}{|c|c|c|}
\hline $\begin{array}{l}\text { Open } \\
\left.\text { (Trawls yr }{ }^{-3}=>10\right) \\
\text { (No. blocks }=69) \\
(34.5 \%)\end{array}$ & $\begin{array}{l}\text { Heavily trawled blocks } \\
\text { Past fishing effort } \\
\text { Seamounts/VMEs } \\
\text { Past seabed impact } \\
\text { Additional blocks closed a } \\
\text { interim measure to protect } \\
\text { areas within this tier. }\end{array}$ & $\begin{array}{l}\text { - high } \\
\text { - yes } \\
\text { - heavy } \\
\text { s precautionary } \\
\text { representative }\end{array}$ \\
\hline $\begin{array}{l}\text { Move-on } \\
\left.\text { (Trawls yr }{ }^{-3}=1-10\right) \\
\text { (No. blocks }=69) \\
(34.5 \%)\end{array}$ & $\begin{array}{l}\text { Moderately trawled bloc } \\
\text { Past fishing effort } \\
\text { Seamounts/VMEs } \\
\text { Past seabed impact } \\
\text { Review of VME encounters } \\
\text { periodically and blocks wit } \\
\text { encounter rates also close }\end{array}$ & $\begin{array}{l}\frac{k s}{- \text { moderate }} \\
\text { - ? } \\
\text { - moderate }\end{array}$ \\
\hline $\begin{array}{l}\text { Closed } \\
\text { Gravis } \mathrm{kr}=81) \\
(\mathrm{No} \text { blocks }=62) \\
(31 \%)\end{array}$ & $\begin{array}{l}\frac{\text { Lightly trawled blocks }}{\text { Past fishing effort }} \\
\text { Seamounts/VMEs } \\
\text { Past seabed impact } \\
\text { Remain closed during the } \\
\text { interim measures. }\end{array}$ & $\begin{array}{l}\text { - negligible } \\
\text { - ? } \\
\text { - negligible } \\
\text { period of the }\end{array}$ \\
\hline
\end{tabular}

Fig. 2. Overview of the 3-tier past-effort classification system adopted by New Zealand as a basis for management of bottom trawling in the New Zealand trawl footprint. VMEs: vulnerable marine ecosystems. Hatching patterns indicate the different management approaches in each tier. Small cross-hatched blocks indicate additional closures in the Open and Move-on tiers 
Table 1. Summary of block closures in New Zealand based on the 3-tier stratification, including the total number of $20 \mathrm{~min}$ latitude $\times 20$ min longitude blocks in each fishing area, the number closed in the lightly fished tier and the number additionally closed in the moderately ( 9 blocks closed) and heavily trawled (11 blocks closed) tiers

\begin{tabular}{|lccc|}
\hline Fishing area & $\begin{array}{c}\text { Total no. of } \\
\text { blocks }\end{array}$ & $\begin{array}{c}\text { Lightly } \\
\text { trawled } \\
\text { closed } \\
\text { blocks }\end{array}$ & $\begin{array}{c}\text { Additional } \\
\text { closures: } \\
\text { moderate \& } \\
\text { heavy areas }\end{array}$ \\
\hline Lord Howe North & 22 & 8 & 2 \\
Lord Howe South & 23 & 12 & 2 \\
Challenger Plateau & 58 & 9 & 6 \\
West Norfolk Ridge & 17 & 6 & 2 \\
Three Kings Ridge & 10 & 4 & 1 \\
Louisville North & 24 & 7 & 3 \\
Louisville Central & 26 & 6 & 2 \\
Louisville South & 16 & 6 & 2 \\
Other areas & 4 & 4 & 0 \\
Total & 200 & 62 & 20 \\
\hline
\end{tabular}

Tier 1: lightly trawled blocks

The 62 lightly trawled blocks have been closed to further fishing. This reduces the area available for future fishing more closely to the actual area fished historically and protects these lightly trawled areas from further impact. A similar approach to benthic protection has been adopted in other regions, such as the open areas approach by the US National Marine Fisheries Service (NMFS) for benthic habitat protection in the Aleutian Islands/Bering Sea groundfish trawl fishery (NMFS 2008). An important purpose of that fishery management plan is to constrain fishing effort to seabed areas already impacted by past fishing, and prevent effort from expanding onto adjacent untrawled or lightly trawled areas (as recommended by Davies et al. 2007). The approach taken by NMFS has been to close any area with $\leq 1$ trawl $100 \mathrm{~km}^{-2}$ during 1998-2005 to further fishing, and any area with $>1$ trawl being designated the open area for fishing. For comparison, the $20 \times 20$ min blocks comprising the New Zealand bottom trawl footprint average $1087 \mathrm{~km}^{2}$ in area, ranging from $1243 \mathrm{~km}^{2}$ in the north to $898 \mathrm{~km}^{2}$ in the south of the footprint, and blocks with $<4$ trawls during 2002-2006 being closed.

Tier 2: moderately trawled blocks

Much of the fishing effort in the 69 moderately trawled (3 to 50 tows) blocks has comprised exploratory fishing in areas adjacent to targeted seamount features. These tend to be flatter, mud-dominated areas and it is largely unknown, but certainly less likely (in terms of habitat suitability), that VMEs occur in these blocks. The move on rule has therefore been applied in these blocks using the rapid VME Identification Protocol described in Parker et al. (2009). Vessels bringing up evidence of a VME (as defined in that protocol) are required to move $5 \mathrm{n}$ miles away from the position where hauling of the gear commenced for any particular tow, and not fish within $5 \mathrm{n}$ miles of that position for the remainder of that fishing trip. Evidence of VMEs in trawl bycatches in each tow is gathered by scientific observers under the $100 \%$ observer coverage requirements for high seas bottom trawling. These observers additionally collect comprehensive benthic bycatch data, quantified and identified to the lowest possible taxon, from every tow in all areas. Data generated by trawls encountering evidence of a VME will be periodically reviewed, together with observer data on detailed benthic bycatch, to ascertain to what extent this evidence of a VME indicates actual existence of VMEs. Additional closures will be considered if consistent and significant evidence indicates existence of VMEs in particular areas (as recommended by Rogers et al. 2008, see Parker et al. 2009 for details).

\section{Tier 3: heavily trawled blocks}

One of the explicit objectives of the New Zealand management approach is to provide for some level of future bottom fishing activity. Of the past fishing effort, $95 \%$ has occurred in the 69 heavily trawled (>50 tows) blocks, much of it targeting certain specific seamount features. These heavily trawled blocks also produced $97 \%$ of the catch during 2002-2006. Given the existing evidence of the substantial impact of bottom trawling on fragile deep-water corals, it is likely that many VMEs in heavily targeted fishing positions in these areas have already been significantly impacted. This has led authors such as Davies et al. (2007) to conclude that, if fishing is to continue in the deep sea, the most immediately effective measure would be to allow fishing to continue in areas where benthic damage has already occurred, but to close other areas to new fishing to protect benthic habitats and fish stocks. This has been the approach taken to benthic habitat protection in the Aleutian Islands/Bering Sea groundfish trawl fishery (NMFS 2008), and was the main principle underpinning the establishment of the SPRFMO bottom fishing footprint.

Most of these heavily fished blocks have therefore been designated as open fishing areas. The move-on rule has not been applied in these blocks, partly to address the concern that such move-on provisions result in steady expansion of fishing effort onto adjacent, previously less impacted areas, and partly to 
focus fishing on already heavily targeted features. Instead, adequate representative protection of VMEs across the spatial scale of each of the distinct fishing areas is being implemented through the closure of the lightly trawled tier, implementation of the move-on rule (with the possibility of further closures if existence of VMEs is demonstrated), plus additional precautionary closures in the moderately and heavily trawled tiers.

\section{Additional block closures}

To address concerns that closures implemented only in the lightly trawled tier would not be adequately representative of seabed features and geodiversity of the open areas, additional representative protection was implemented in the heavily and moderately trawled tiers in the form of an additional 20 block closures (10\% of the total footprint blocks), 9 in the moderately trawled and 11 in the heavily trawled areas. The 20 additional block closures were specifically selected to be representative of the open areas in terms of depth range and topography, using high-resolution bathymetry provided by industry for the purpose of the consultations.

The resulting distribution of closures across fishing areas is summarised in Table 1 and shown in Fig. 1. The lightly trawled block closures are distributed across all fishing areas in inverse proportion to the level of past fishing effort in each area. A smaller proportion of the blocks have remained lightly trawled in heavily trawled areas such as the Challenger Plateau, so a smaller proportion of blocks in that area $(16 \%)$ have been closed. In contrast, a high proportion of blocks have been lightly trawled and closed in more lightly trawled areas such as the West Norfolk Ridge (35\% closed), Three Kings Ridge (40\% closed) and Lord Howe Rise (44\% closed). Lightly trawled block closures along the Louisville Ridge range from $23 \%$ of blocks for the most heavily trawled central area to $38 \%$ of blocks in the more lightly trawled southern area.

Additional closures in the moderately and heavily trawled tiers were intentionally distributed in proportion to the number of heavily trawled blocks in each area to ensure proportional protection by these additional closures between fishing areas. The largest number of additional closures was therefore made in the Challenger Plateau (6 blocks), decreasing to 1 additional closure in the Three Kings Ridge area. Over the entire bottom trawl footprint, $31 \%$ of the blocks were closed due to being lightly trawled; with additional closures this brings the total proportion closed to $41 \%$ (82 of the 200 blocks).

\section{EVALUATING REPRESENTATIVITY OF SPATIAL CLOSURES}

Adequate and representative spatial closures have been recognized as probably the most effective longterm VME protection measure by the SPRFMO Science Working Group (SPRFMO 2007c) and the FAO Technical Consultation on International Guidelines for the Management of Deep-sea Fisheries in the High Seas (FAO 2008). Recent IUCN recommendations on protection of seamounts and deep-sea VMEs recommend a minimum closure of 30 to $40 \%$ of such areas (Rogers et al. 2008), although some estimates suggest that a precautionary approach may require 50 to $90 \%$ of the total habitat to be protected (Clark 1996, Lauck et al. 1998). One of the main questions that arose during consultations and risk assessment of the 3-tier management approach and proposed closures was whether proposed closed areas were representative of the open areas in terms of likelihood of supporting VMEs, and whether these closures would be sufficient to constitute adequate and representative protection across the spatial scale of the bottom trawl footprint or the SPRFMO Area (MFish 2008).

Given adequate time and funding to conduct the necessary seabed biodiversity surveys, spatial protection measures should be designed around protection of areas demonstrated to be highly biodiverse; this approach has been strongly advocated in the design of inshore marine protected areas (MPAs). In deep-water areas, protection of the Darwin Mounds northwest of Scotland after demonstration that these mounds were colonised by a diverse community of corals, suspension feeders and infauna (Van Gaever et al. 2004) is cited as an example of the approach which should be adopted (Davies et al. 2007). However, data on seabed biodiversity are lacking for most deep-sea benthic areas, and are unlikely to be collected except for a few seamount systems, so an alternate approach is required. Initially, bathymetric information was used to define, identify and delineate geomorphic units or characteristic seabed features, such as seamounts; spatial protection proposals were then stratified by these units (e.g. Harris 2007). The prevalence of this approach is reflected in the FAO Guidelines for Management of Deep-sea Fisheries (FAO 2008), which specifically define VMEs in terms of seabed features likely to support vulnerable species.

However, Williams et al. (2009) have demonstrated that reliance on geodiversity alone results in false assumptions of homogeneity within geomorphic units, unless other factors of biological importance are taken into consideration. They found that the most important of these factors are depth, feature size and topographic complexity, which strongly influence biodiversity 
within a feature class. Noting the general paucity of high-seas biodiversity data, a series of workshops to develop guidelines for the design of MPA networks for seamounts and the Abyssal Nodule Province in the Pacific high seas (Clark et al. 2009) distilled habitat suitability classification approaches (such as Hirzel et al. 2002, Clark et al. 2006) and recommendations regarding key factors to include when evaluating geomorphic features as surrogates for seabed biodiversity (e.g. Williams et al. 2009) into recommendations for stratification of deep-sea spatial closures to represent key biologically important factors of importance to cold-water corals.

The following 4 main recommended key factors were used to stratify and evaluate representativity of the spatial closures within the New Zealand bottom trawl footprint.

\section{Stratification by biogeographic zone}

At the highest level, spatial closures should reflect oceanographic conditions of water masses in large ocean areas, such as the Southwest Pacific Ocean. Fishing areas in the Tasman Sea and the Southwest Pacific Ocean occupy, at most, 2 different biogeographic zones. The requirement of stratifying representative benthic protection measures by biogeographic zone (Clark et al. 2009) is therefore automatically dealt with by stratifying closures between the fishing areas, with the Lord Howe Rise, Challenger Plateau, West Norfolk Ridge and Three Kings Ridge fishing areas in the Tasman Sea, and the Louisville Ridge in the Southwest Pacific Ocean.

\section{Stratification by proximity and/or connectivity}

The distance between underwater topographic features and the relationship of seamount direction to current flow affect the abilities of fauna to disperse and colonize adjacent seamounts. The separation distance indicating a separate feature has been proposed as 100 to $200 \mathrm{~km}$ and Clark et al. (2009) recommend 2 ranges: close (<100 km separation) and distant (>100 km separation) as appropriate strata for precautionary conservation in the central Pacific region. Under the New Zealand approach, stratification of spatial closures to represent the various fishing areas also addresses the recommendation to stratify spatial closures by proximity and/or connectivity. The Tasman Sea fishing areas are about $150 \times 300 \mathrm{~km}$ in size, with separation between them ranging from about 50 to $250 \mathrm{~km}$. The 3 areas along the Louisville Ridge are about $120 \mathrm{~km}$ wide, and are separated by a similar distance.

\section{Stratification by depth range}

After geomorphology (feature types), depth has been found to be a major determinant of species composition, particularly on deep-sea seamount features with high elevation (Clark \& Rowden 2009, Williams et al. 2009). Elevation above the abyssal plain (which typically lies at $\sim 4000 \mathrm{~m}$ deep in the South Pacific Ocean) is also a relative measure of seamount size. The following depth strata were adopted for the purposes of evaluating the New Zealand bottom trawl closures, modified slightly from those recommended by Clark et al. (2009) to divide strata at $2000 \mathrm{~m}$, the current maximum trawlable depth:

(1) 0 to $200 \mathrm{~m}$ : this stratum covers the protrusion of a seabed feature into the photic zone.

(2) 201 to $800 \mathrm{~m}$ : this stratum covers the depth range of the scattering layer, composed of vertically migrating animals, and the impact of these on the fauna that exists on seamount summits. The upper limit, $800 \mathrm{~m}$, is the upper bathyal split proposed by Zezina (1997).

(3) 801 to $2000 \mathrm{~m}$ : this stratum covers part of the 800 to $3500 \mathrm{~m}$ depth band recognized in the Global Open Oceans and Deep-sea habitats (GOODs) bioregional classification (Vierros et al. 2008) as the lower bathyal biogeographic zone, as assigned by Zezina (1997) based on a global evaluation of brachiopods. The lower bathyal zone has been divided at $2000 \mathrm{~m}$, the current maximum trawlable depth, for the purpose of designing representative closures in the bottom trawl footprint.

(4) > $2000 \mathrm{~m}$ : this is the stratum below current trawling technology, and currently beyond impact by deepwater trawling.

\section{Stratification by topography}

Seabed topography is an indicator of seabed geology, and therefore of substratum suitability for supporting VME species, and provides the primary basis for geomorphological classification of specific seabed feature classes (such as seamounts, canyons or ridges). The FAO (2008) specifically recognizes the following as being features that potentially support species, groups or communities which may contribute to forming VMEs: submerged edges and slopes; summits and flanks of seamounts, guyots, banks, knolls, and hills; and canyons, trenches and hydrothermal vents.

\section{Representativity of spatial closures by depth}

Representativity of the New Zealand interim spatial closures by depth and topography were evaluated using bathymetric data. Additional block closures were 
selected to be representative of topography and depth range of open areas within each fishing area, based on high-resolution industry bathymetric data of trawled areas. Representativity of closed areas in relation to the SPRFMO Area was evaluated using the 2008 global 1 min resolution gridded bathymetry available from the General Bathymetric Chart of the Oceans (GEBCO, www.gebco.net). Data were extracted for the SPRFMO Area $\left(0^{\circ}\right.$ to $60^{\circ} \mathrm{S}, 120^{\circ} \mathrm{E}$ to $\left.70^{\circ} \mathrm{W}\right)$ and regridded at $3 \mathrm{~min}$ resolution using MapInfo Vertical Mapper ${ }^{\circledR}$. Simple rectangular gridding (which averages nearby depths at the new grid resolution) was used to avoid introducing any further gridding artefacts. These regridded depth data were contoured using $\mathrm{MapInfo}^{\circledR}$ to produce closed contour regions at intervals of $200 \mathrm{~m}$ from which areas by depth could be calculated, and split into regions which fall within the SPRFMO Area and those which fall into Exclusive Economic Zones (EEZs) adjacent to the SPRFMO Area.

Histograms of the resulting $200 \mathrm{~m}$ depth frequency distributions are shown in Fig. 3 for EEZs and the SPRFMO Area. The seabed in the SPRFMO Area primarily covers the depth range 2800 to $5600 \mathrm{~m}$, with a strong mode at the depth of the abyssal plain from 4000 to $4600 \mathrm{~m}$. Many South Pacific countries have extensive deep areas within their EEZs, and EEZ seabed depths cover a wider range than the SPRFMO Area, extending from the shore out to the $10000 \mathrm{~m}$ deep Kermadec Trench within the New Zealand EEZ. Notably, most of the South Pacific seabed at depths $<3200$ m lies within EEZs, with a high proportion of the trawlable depths $<2000 \mathrm{~m}$ lying on continental shelves and slopes within EEZs.

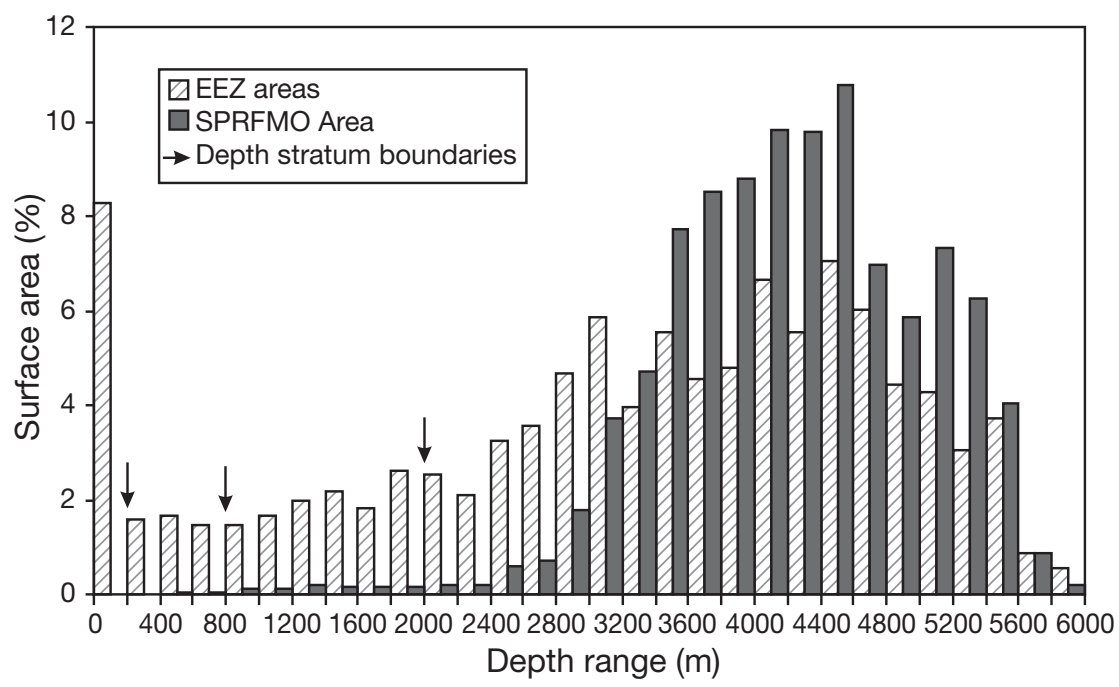

Fig. 3. Depth frequency distributions (200 $\mathrm{m}$ depth ranges) of the seabed in the proposed South Pacific Regional Fisheries Management Organisation (SPRFMO) Area and in directly adjacent exclusive economic zones (EEZs), showing boundaries of the depth strata used for evaluating representativity of closed areas by depth
Table 2 provides a summary of the calculated area within each of the depth protection strata recommended by Clark et al. (2009), and the depth boundaries of these strata are indicated in Fig. 3. Most EEZ and SPRFMO areas lie below trawlable depth, but there are substantial differences between the SPRFMO Area and EEZs in the trawlable depth ranges. Less than $1 \%$ of the SPRFMO Area is $<2000 \mathrm{~m}$ deep, whereas $23 \%$ of EEZs are shallower than $2000 \mathrm{~m}$. Across the whole South Pacific, almost $100 \%$ of the 0 to $200 \mathrm{~m}$ depth range lies within EEZs, as does $98 \%$ of the 200 to $800 \mathrm{~m}$ range and $90 \%$ of the 800 to $2000 \mathrm{~m}$ range. Overall, $94 \%$ of the trawlable depth range of 0 to $2000 \mathrm{~m}$ lies within EEZs and coastal states clearly have an important role to play in protecting VMEs on seabed areas at trawlable depths within their EEZs.

The distribution of areas $<2000 \mathrm{~m}$ deep within the SPRFMO Area is mapped in Fig. 4. Areas of trawlable depth are isolated and largely confined to the Lord Howe Rise, Challenger Plateau and West Norfolk Ridge, and the scattered seamount chains forming the Louisville, Foundation, Salas y Gómez and Nazca Ridges. Fig. 1 shows the distribution of depths $<2000 \mathrm{~m}$ in relation to the New Zealand bottom trawl footprint. Although the bottom trawl footprint only covers $0.4 \%$ of the total SPRFMO Area, it covers all of the Area from 0 to $200 \mathrm{~m}$ depth, $90 \%$ of the Area from 200 to $800 \mathrm{~m}$ and $22 \%$ of the Area from 800 to $2000 \mathrm{~m}$ (Table 3). In total, footprint areas $<2000 \mathrm{~m}$ deep cover $28 \%$ of the SPRFMO Area $<2000 \mathrm{~m}$ deep. There is therefore a clear obligation for SPRFMO participants to protect VMEs that may occur in the high proportion of trawlable depth areas that occur within the bottom trawl footprint.

To compare depth ranges within closed, move-on and open footprint blocks, the distribution of depth ranges within each footprint block was evaluated using the original $1 \mathrm{~min}$ GEBCO gridded bathymetry data, which provides $\sim 400$ evenly spaced depth grid points for each footprint block. Assuming each point within a block represents an equal area of the footprint block concerned, the surface areas of each $200 \mathrm{~m}$ depth range within each footprint block were calculated and compared with the depth distributions in the SPRFMO Area.

The extent to which New Zealand has protected representative depth ranges within the spatial closures is detailed in Table 3, which summarises the proportion of the footprint within each depth range which has 
Table 2. Estimated total sea surface area within various depth ranges in the South Pacific Regional Fisheries Management Organisation (SPRFMO) Area and within the exclusive economic zones (EEZs) of adjacent countries

\begin{tabular}{|c|c|c|c|c|}
\hline \multirow{2}{*}{$\begin{array}{l}\text { Depth } \\
\text { range (m) }\end{array}$} & \multicolumn{2}{|c|}{- EEZs } & \multicolumn{2}{|c|}{- SPRFMO } \\
\hline & Area $\left(\mathrm{km}^{2}\right)$ & Area (\%) & Area $\left(\mathrm{km}^{2}\right)$ & Area $(\%)$ \\
\hline $0-200$ & 3109166 & 7.6 & 552 & 0.001 \\
\hline $200-800$ & 1770889 & 4.3 & 43101 & 0.1 \\
\hline $800-2000$ & 4392874 & 10.8 & 497305 & 0.9 \\
\hline$>2000$ & 31453950 & 77.2 & 53309911 & 99.0 \\
\hline Total & 40740704 & 100 & 53850868 & 100 \\
\hline
\end{tabular}

been closed, made subject to a move-on rule or left open. All of the 0 to $200 \mathrm{~m}$ depth range has been closed. A total of $84 \%$ of the 200 to $800 \mathrm{~m}$ depth range and $63 \%$ of the 800 to $2000 \mathrm{~m}$ depth range have been closed or made subject to a move-on rule. In addition, the entire depth range deeper than $2000 \mathrm{~m}$ is effectively closed as a result of being beyond trawlable depths. These deep areas within the footprint have nonetheless been explicitly closed, as a result of falling within lightly trawled blocks. Overall, $68 \%$ of the 0 to $2000 \mathrm{~m}$ depth range and $71 \%$ of the total depth range within the footprint has been protected in some way, either by closure or by implementation of move-on provisions.

The percentage of each fishing area/depth stratum which has been protected either by precautionary closures or by implementation of a move-on rule is summarised in Fig. 5, which shows the percentage of each stratum protected within each fishing area in relation to recommended levels of $30 \%$ (Rogers et al. 2008) and
Table 3. Proportion of the New Zealand bottom trawl footprint covering various depth strata within the South Pacific Regional Fisheries Management Organisation (SPRFMO) Area, showing relative proportions of closed, move-on and open areas within each stratum

\begin{tabular}{|lrcccc|}
\hline $\begin{array}{l}\text { Depth } \\
\text { range } \\
(\mathrm{m})\end{array}$ & $\begin{array}{c}\text { SPRFMO } \\
\text { area } \\
\left(\mathrm{km}^{2}\right)\end{array}$ & \multicolumn{3}{c|}{$\begin{array}{l}\text { Bottom trawl footprint (\%) } \\
\text { Closed Move-on Open }\end{array}$} & $\begin{array}{c}\text { Footprint } \\
\text { total } \\
(\%)\end{array}$ \\
\hline $0-200$ & 552 & 100.0 & 0.0 & 0.0 & 100.0 \\
$200-800$ & 43101 & 35.5 & 40.0 & 14.6 & 90.0 \\
$800-2000$ & 497305 & 9.0 & 4.9 & 8.2 & 22.0 \\
$>2000$ & 53309911 & 0.1 & 0.0 & 0.0 & 0.1 \\
Total & 53850868 & 0.2 & 0.1 & 0.1 & 0.4 \\
\hline
\end{tabular}

$50 \%$ (Clark 1996, Lauck et al. 1998). The fishing areas differ in depth range, with plateau areas like the Lord Howe Rise and Challenger Plateau having narrower depth ranges than the ridge and seamount chain systems. Much of the footprint on these plateaus lies within the actively targeted and heavily fished trawl depth range of 400 to $1600 \mathrm{~m}$ (MFish 2008). Depths on the West Norfolk Ridge span the widest range, including most of the high seas area shallower than $200 \mathrm{~m}$ and some areas deeper than $2000 \mathrm{~m}$ adjacent to the ridge itself. Most of the seabed in the Three Kings and Louisville Ridge areas lies below 2000 m, with limited areas of trawlable depth, particularly along the Louisville seamount chain.

Across the entire footprint, more than half of each $200 \mathrm{~m}$ depth range has either been closed or made subject to a move-on provision, the least being $58 \%$ of the

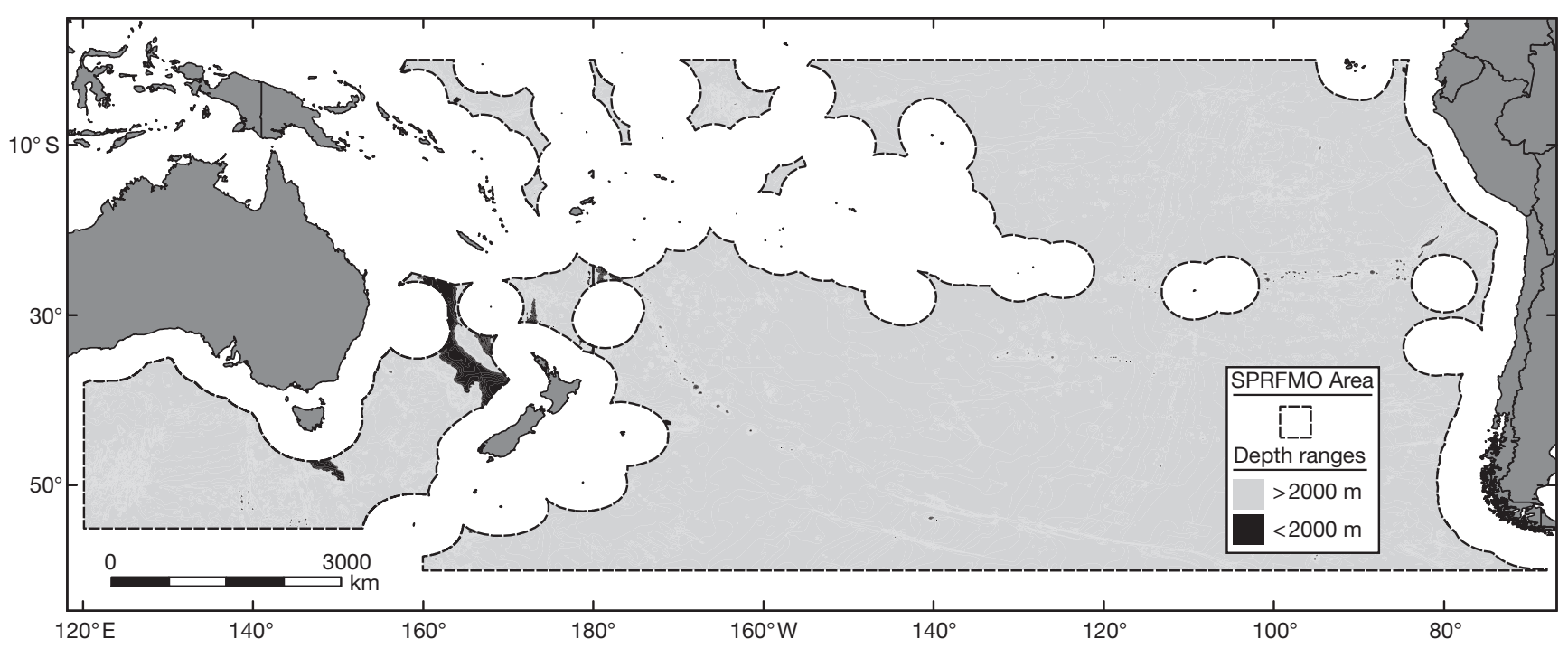

Fig. 4. Map of the proposed South Pacific Regional Fisheries Management Organisation (SPRFMO) Area showing the proportion of the SPRFMO Area deeper than $2000 \mathrm{~m}$ (99\% of the SPRFMO Area, light grey) and shallower than $2000 \mathrm{~m}$ (1\% of the SPRFMO Area, black). Areas within national exclusive economic zones are white. Trawlable areas (<2000 m depth) are largely confined to the South Tasman Rise, Lord Howe Rise, Challenger Plateau and the West Norfolk, Three Kings, Louisville, Foundation, Salas y Gomez and Nazca Ridges 


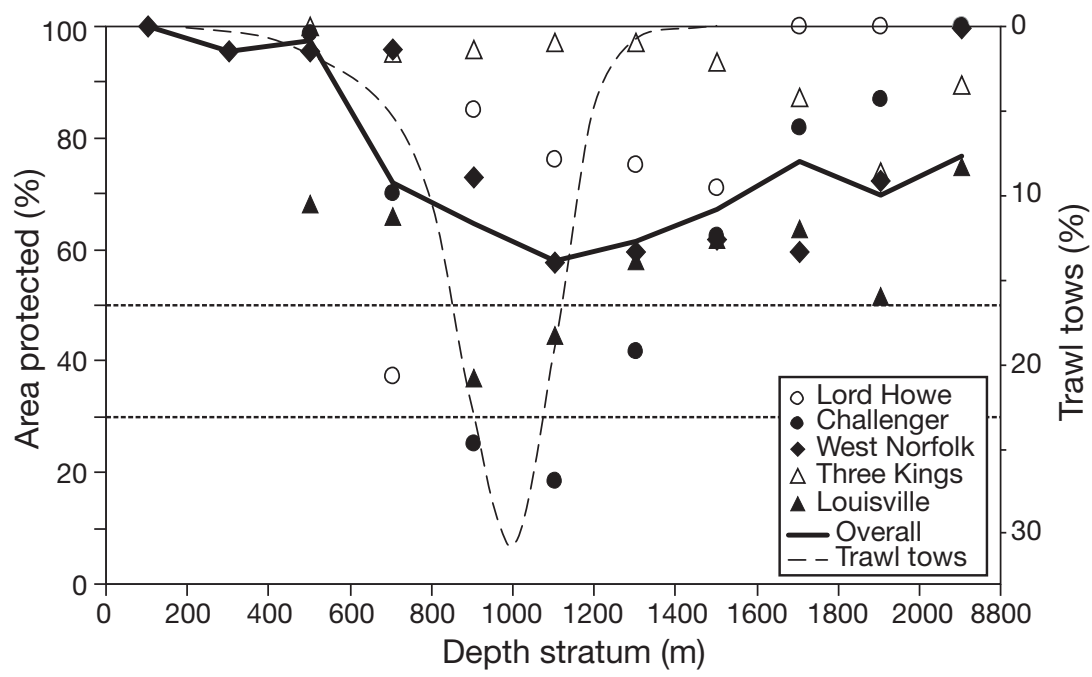

Fig. 5. Percent of each fishing area by $200 \mathrm{~m}$ depth stratum in the New Zealand bottom trawl footprint that has been protected, either by precautionary closure or by move-on provisions, in relation to recommended protection levels (horizontal dotted lines) of 30\% (Rogers et al. 2008) and 50\% (Clark 1996, Lauck et al. 1998). The solid line shows the percent protected by $200 \mathrm{~m}$ depth range across the entire footprint. The dashed line shows the distribution of fishing effort by $200 \mathrm{~m}$ depth stratum

1000 to $1200 \mathrm{~m}$ depth range. However, the proportion of protected area by $200 \mathrm{~m}$ depth range differs between fishing areas depending on intensity of past fishing effort in each area. Only $27 \%$ of the main targeted depth range of 800 to $1400 \mathrm{~m}$ on the Challenger Plateau has been protected, including $<20 \%$ of the 1000 to $1200 \mathrm{~m}$ depth range, and $37 \%$ of the 600 to $800 \mathrm{~m}$ depth range on the Lord Howe Rise and $41 \%$ of the 800 to $1200 \mathrm{~m}$ depth range on the Louisville Ridge have been protected. This is a direct consequence of the higher levels of past (2002-2006) fishing effort in these areas and the management decision to leave such areas open to focus future trawling effort on those historically most impacted areas.

\section{Representativity of spatial closures by topography}

Seamounts

Given the emphasis in the UNGA Resolution 61/105 (UNGA 2007), the SPRFMO interim measures and the FAO Deepwater Guidelines (FAO 2008) on protection of seamounts as features likely to support VMEs, an evaluation of the representativity of footprint closures in protecting topographic features was conducted using available data on distribution of seamounts in the South Pacific Ocean. Two data sets were used, the Kitchingman \& Lai (2004) database of predicted seamounts and the Allain et al. (2008) database of validated seamounts occurring within the SPRFMO Area.
Of the total 4126 Kitchingman \& Lai (2004) seamounts occurring in the South Pacific Ocean $\left(0\right.$ to $60^{\circ} \mathrm{S}, 120^{\circ} \mathrm{E}$ to $\left.70^{\circ} \mathrm{W}\right)$, $2541(62 \%)$ occur within the EEZs of countries bordering the SPRFMO Area, and $1585(38 \%)$ occur within the SPRFMO Area. This is a consequence of the volcanic nature of the region, the result of which is that many South Pacific countries, particularly small Pacific island countries, have numerous seamounts within their EEZs. Coastal States therefore have an important role to play in protecting VMEs in the South Pacific region. (In recognition of this obligation, New Zealand implemented a Seamounts Management Strategy in 2001 [Brodie \& Clark 2004], followed by closure of Benthic Protection Areas in 2007; www.fish.govt.nz/en-nz/environmental/). The combination of these measures now protects $32 \%$ of the New Zealand EEZ, $28 \%$ of underwater topographic features, $52 \%$ of known largescale ( $>1000 \mathrm{~m}$ height) seamounts and $88 \%$ of active geothermal vents.

Within the SPRFMO Area itself, Allain et al. (2008) have validated the existence and positions of 1450 seamount features. Of these, $97 \%$ lie outside the New Zealand bottom trawl footprint, 42 lie within the footprint and $18(1.2 \%)$ lie within the open footprint blocks. Therefore, $57 \%$ of the known seamounts occurring within the trawl footprint are protected either by closures or move-on provisions.

\section{General seabed topography}

In addition to the GEBCO 1 min bathymetric grid data, higher resolution (30 arc-second) data are available from Geoscience Australia (www.ga.gov.au) for the Tasman Sea region. These 2 data sets were used to generate highest available resolution bathymetric grid maps of the individual fishing areas using MapInfo Vertical Mapper ${ }^{\circledast}$. Three-dimensional digital terrain surfaces draped with the New Zealand bottom trawl footprint were generated for each fishing area to facilitate visual comparison of topography of the closed, move-on and open blocks in each area. Cross-sectional profiles across the various fishing areas were then used to evaluate the extent to which closed areas, and areas outside the bottom trawl footprint, are representative, in terms of depth range and seabed topography, of the areas left open to bottom trawling. We present of 2 of the areas here as examples, Three Kings and West 
Norfolk Ridges, to illustrate the process which was conducted for all areas (see MFish 2008).

\section{Three Kings Ridge}

The Three Kings Ridge fishing area lies along the western edge of the Fiji Basin and is surrounded by a large number of relatively isolated, steep, high-profile seamounts (Fig. 6). Most of the high-profile and likely high-biodiversity features in this area lie outside the footprint, and have remained untrawled, as has much of the ridge feature itself. Along the ridge area within the footprint, only one block remains open to fishing. The combination of closed, move-on and outsidefootprint surrounding areas protect most of the shallower, high-profile areas in the northern part of this area. The one additional block closure plus one moveon block afford complete protection of the southern part of this area, including the shallowest feature.

\section{West Norfolk Ridge}

The West Norfolk Ridge is a complex, rugged and high-profile area of hills, steep flanks and canyons, dominated by 2 parallel ridge features running roughly north-south (Fig. 7). The shallowest and highest profile of these in the northeast of the area is a primary target area for bottom long-line vessels targeting bluenose Hyperoglyphe antarctica and wreckfish (mainly Polyprion americanus with some $P$. oxygeneios) on steep rocky features along this ridge. This ridge area has remained relatively untrawled and one additional block closure has resulted in most of the eastern ridge being closed to trawling. Trawling has focused on features in the southeast and central parts of the area. The topography and depth range of the open blocks are well represented by the eastern ridge closure, the move-on blocks covering the shallowest part of the central area and the additional block closure on the central canyon between the ridges. To the west, the southwest block closure protects a particularly steep flank area. Together with the move-on blocks, the entire high profile western flank is currently protected.

\section{DISCUSSION}

The mitigation measures to prevent significant adverse impacts from bottom trawling in the New Zealand bottom trawl footprint are a combination of closure of all lightly trawled blocks, application of the move-on rule in moderately trawled blocks, plus additional precautionary closures of representative blocks in the moderately and heavily trawled areas, with the potential future closure of further blocks found to contain significant evidence of VMEs. Advantages of this approach are that representative trawled areas and unimpacted areas are closed to provide protection to likely VMEs from the outset, rather than relying on a move-on rule and subsequent analyses before closing areas. The clear definition of open and closed areas provides certainty to industry and facilitates compliance. The approach also supports data collection as information on fishing impacts and regeneration rates can be monitored. The combination of limited footprint, representative precautionary closures and the move-on rule are intended to constitute adequate protection measures during the interim period.

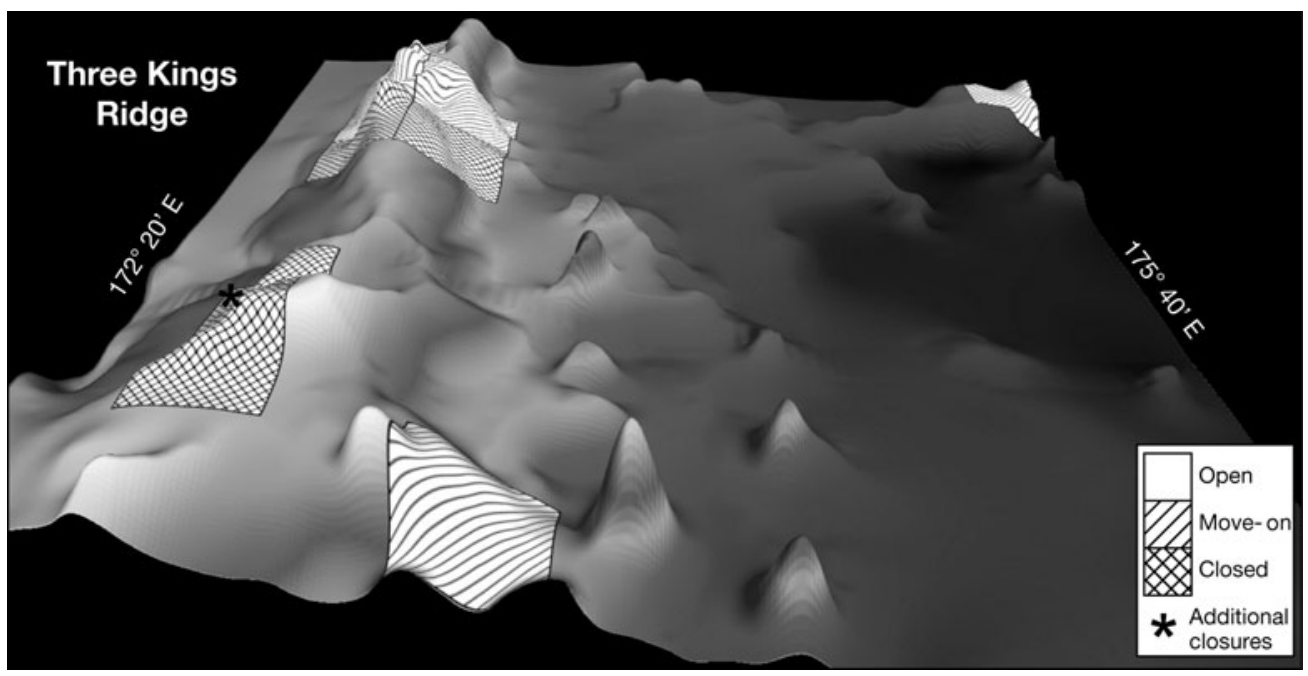

Fig. 6. Three-dimensional seabed topography in the Three Kings Ridge fishing area showing the distribution of open, move-on and closed bottom trawl footprint blocks (20 min latitude $\times 20$ min longitude) and ridge/seamount features outside the footprint. *: additional representative closures of moderately and heavily trawled blocks 


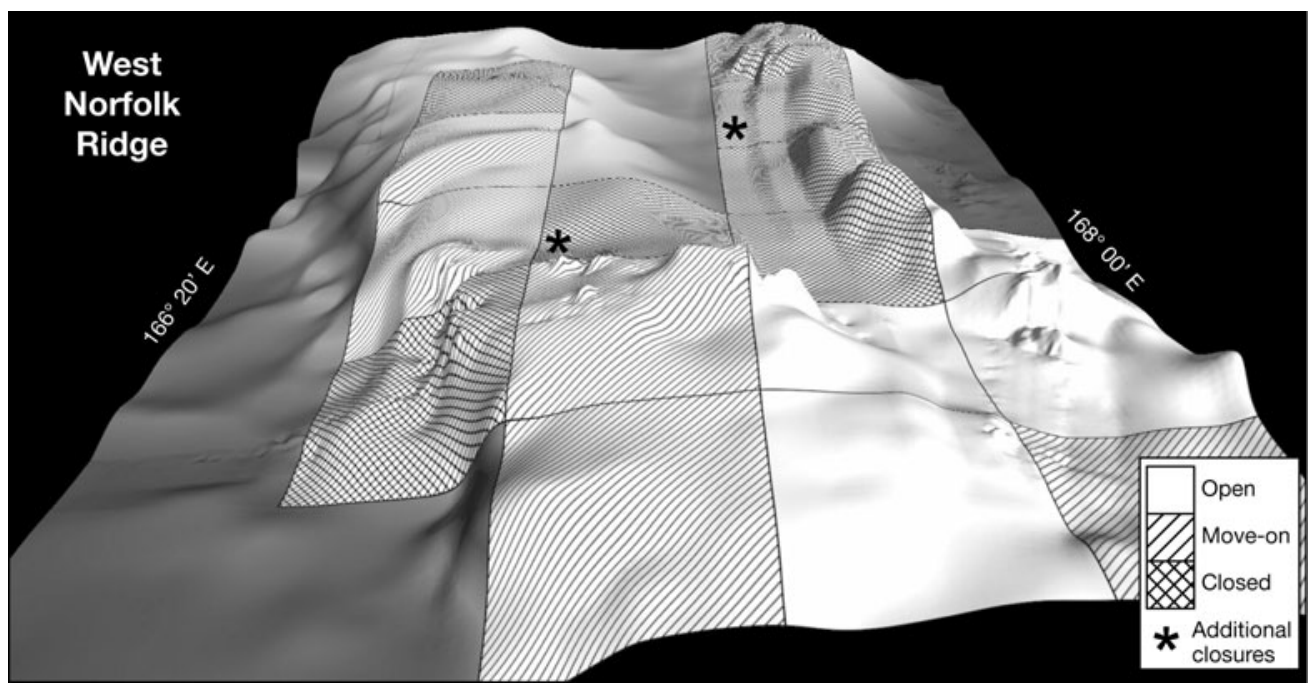

Fig. 7. Three-dimensional seabed topography in the West Norfolk Ridge fishing area showing the distribution of open, move-on and closed bottom trawl footprint blocks (20 min latitude $\times 20$ min longitude) and ridge areas outside the footprint. *:additional representative closures of moderately and heavily trawled blocks

Comparing the approach taken by New Zealand to measures implemented by other RFMOs, the approach taken by the North East Atlantic Fisheries Commission (NEAFC) to protect VMEs in the Mid-Atlantic Ridge is similar. The NEAFC recognizes that detailed information on species composition, habitat association, seabed geology and bathymetry are not available, and considers that some areas have already been substantially impacted by fishing (NEAFC 2008, PECMAS 2008). However, whereas the NEAFC closures are targeted at specific seamounts and areas where corals are known from surveys, the New Zealand approach is broader, using available information on fishing intensity, connectivity, depth zones, biogeographic zones and topography to design representative spatial protection measures across the full extent of the fishing footprint, as recommended by Williams et al. (2009). To the extent that the FAO provides a method for designation of VMEs, the New Zealand approach complies in a more explicit manner than the NEAFC closure scheme. The New Zealand approach has also implemented far more conservative encounter rules (Parker et al. 2009) in comparison with the NEAFC and the Northwest Atlantic Fisheries Organization thresholds of $1000 \mathrm{~kg}$ of sponge or $100 \mathrm{~kg}$ of coral per set.

However, these are only intended to be interim measures, to try and provide adequate and representative protection to areas likely to support VMEs during the period of the interim measures. In the long term, effective protection of benthic VMEs in the Pacific Ocean high seas will probably require the establishment of a series of international spatial closures designed to protect adequate and representative areas of habitats and ecosystems. There is evidence in the Atlantic Ocean that community composition can vary substantially among features and that communities may not be widely distributed, which would weaken the representative approach taken by New Zealand and the NEAFC (Hall-Spencer et al. 2007, Watling 2007, ICES 2008). However, the broad biodiversity distributional data needed to make more informed protection decisions is not available in the North Atlantic and distributional data from the South Pacific is even more sparse.

In this context, the recommendations of Williams et al. (2009), regarding the need to adopt an approach which integrates high-resolution data on seabed geomorphology, depth and topographic complexity with limited survey data on seabed biodiversity to jointly define patterns in biodiversity and abiotic variables, are particularly relevant. Such approaches offer the advantage of providing a classification that preserves the information of both data sets, maximizing the potential for predicting patterns in biodiversity from abiotic variables. Integration of survey biodiversity data, observer benthic bycatch information and biologically important physical data forms the foundation of habitat suitability and niche-factor analysis models (Hirzel et al. 2002), which have already been used to predict habitat suitability for cold-water corals within the New Zealand EEZ (Clark et al. 2006, Clark \& Rowden 2009), in the South Pacific Ocean (Allain et al. 2008) and in the Northern Hemisphere (Davies et al. 2008). Over the next few years, New Zealand will be evaluating such approaches to develop international recommendations for permanent representative spatial closures to protect VMEs and low productivity resources in the South Pacific Ocean. 
Acknowledgements. We thank M. Clark for helpful discussions and for reviewing the project. J. Willing and B. Sims are thanked for their guidance and assistance regarding international fisheries policies and obligations. The paper benefited from the constructive criticism of reviewers.

\section{LITERATURE CITED}

Abdulla A, Gomei M, Hyrenbach D, Notarbartolo-di-Sciara G, Agardy T (2009) Challenges facing a network of representative marine protected areas in the Mediterranean: prioritizing the protection of underrepresented habitats. ICES J Mar Sci 66:22-28

Allain VJA Kerandel, Clark M (2008) Potential seamount location in the South Pacific RFMO Area: prerequisite for fisheries management and conservation in the high seas. SPRFMO-V-SWG-05, Secretariat of the Pacific Community, Noumea

Brodie S, Clark MR 2004. The New Zealand seamount management strategy-steps towards conserving offshore marine habitat, In: Beumer, JP, A Grant, DC Smith (eds), Aquatic protected areas: What works best and how do we know? Proceedings of the World Congress on Aquatic Protected Areas, Cairns, 14-17 August 2002. Australian Society for Fish Biology, Hobart, p 664-673

Clark CW (1996) Marine reserves and the precautionary management of fisheries. Ecol Appl 6:369-370

Clark MR, Rowden AA (2009) Effect of deepwater trawling on the macro-invertebrate assemblages of seamounts on the Chatham Rise, New Zealand. Deep-Sea Res I 56:1540-1554

Clark MR, Tittensor D, Rogers AD, Brewin P and others (2006) Seamounts, deep-sea corals and fisheries: vulnerability of deep-sea corals to fishing on seamounts beyond areas of national jurisdiction. UNEP-WCMC, Cambridge

Clark MR, Watling L, Smith C, Rowden AA, Guinotte J, Ardron J (2009) Seamount classification: steps towards global MPA network design. Submission and presentation to Convention on Biological Diversity: expert workshop on scientific and technical guidance on the use of biogeographic classification systems and identification of marine areas beyond national jurisdiction in need of protection. Ottawa, Canada, Sep-Oct 2009

Davies AJ, Roberts JM, Hall-Spencer J (2007) Preserving deep-sea natural heritage: emerging issues in offshore conservation and management. Biol Conserv 138:299-312

Davies AJ, Wisshak M, Orr JC, Roberts JM (2008) Predicting suitable habitat for the cold-water coral Lophelia pertusa (Scleractinia). Deep-Sea Res I 55:1048-1062

FAO (Food and Agricultural Organisation of the United Nations) (2008) International guidelines for the management of deep-sea fisheries in the high seas. Annex 1 of the Report of the Technical Consultation on International Guidelines for the Management of Deep-sea Fisheries in the High Seas. 4-8 February and 25-29 August 2008. FAO Fisheries and Aquaculture Report No. 881, FAO, Rome, p 52

Hall-Spencer J, Rogers A, Davies J, Foggo A (2007) Deep-sea coral distribution on seamounts, oceanic islands, and continental slopes in the Northeast Atlantic. Bull Mar Sci 81(Suppl 1):135-146

Harris PT (2007) Application of geophysical information to the design of a representative system of marine protected areas in southeastern Australia. In: Todd BJ, Greene HG (eds) Mapping the seafloor for habitat characterization. Special Paper 47, Geological Association of Canada, St. John's, NL, p 463-481
Hirzel AH, Hausser J, Chessel D, Perrin N (2002) Ecologicalniche factor analysis: How to compute habitat-suitability maps without absence data? Ecology 83:2027-2036

ICES (2008) Report of the ICES-NAFO Joint Working Group on Deep Water Ecology (WGDEC). 10-14 Mar 2008, Copenhagen, Denmark. ICES CM 2008/ACOM:45, ICES, Copenhagen

Kitchingman A, Lai S (2004) Inferences on potential seamount locations from mid-resolution bathymetric data. In: Morato T, Pauly D (eds) Seamounts: biodiversity and fisheries. UBC Fisheries Centre, Vancouver, BC, p 261

Lauck T, Clark CW, Mangel M, Munro GR (1998) Implementing the precautionary principle in fisheries management through marine reserves. Ecol Appl 8:S72-S78

MFish (Ministry of Fisheries) (2008) Bottom fishing activities by New Zealand vessels fishing in the high seas in the SPRFMO Area during 2008 and 2009. SPRFMO Bottom Fishery Impact Assessment, New Zealand Ministry of Fisheries, Wellingtion

NEAFC (North East Atlantic Fisheries Commission) (2008) Report of the 27th annual meeting of the North East Atlantic Fisheries Commission, 10-14 November 2008, Vol I. North East Atlantic Fisheries Commission, London, available at www.neafc.org/system/files/\%252Fhome/ neafc/drupal2_files/27neafc_annual_2008_vol1_main-report. pdf

NMFS (National Marine Fisheries Service) (2008) Environmental assessment / regulatory impact review / final regulatory flexibility analysis for Amendment 89 to the fishery management plan for groundfish of the Bering Sea and Aleutian Islands Management Area and regulatory amendments for Bering Sea habitat conservation. EA-RIRFRFA Report, National Marine Fisheries Service,

Parker SJ, Penney AJ, Clark MR (2009) Detection criteria for managing trawl impacts to vulnerable marine ecosystems in high seas fisheries of the South Pacific Ocean. Mar Ecol Prog Ser 397:309-317

PECMAS (2008) Permanent Committee on Management and Science-report of the Meeting 17-18 June 2008, Annex 2. North East Atlantic Fisheries Commission, London, available at www.neafc.org/system/files/\%252Fhome/ neafc/drupal2_files/annex2+from+june_08.pdf

Rogers AD, Clark MR, Hall-Spencer JM, Gjerde KM (2008) The science behind the guidelines: a scientific guide to the FAO draft international guidelines (December 2007) for the management of deep-sea fisheries in high seas and examples of how the guidelines may be practically implemented. IUCN, Switzerland

SPRFMO (South Pacific Regional Fisheries Management Organisation) (2007a) SPRFMO III Report-Annex F: interim measures adopted by participants in negotiations to establish South Pacific regional fisheries management organisation. SPRFMO III, 30 Apr to 4 May 2007, Reñaca, Chile. South Pacific Regional Fishery Management Organisation, Wellington

SPRFMO (2007b) SPRFMO IV Report-Annex C: benthic assessment framework. SPRFMO IV, 4-7 Sep 2007, Noumea, New Caledonia. South Pacific Regional Fishery Management Organisation, Wellington

SPRFMO $(2007 \mathrm{c})$ Report of the Fourth Meeting of the SPRFMO Science Working Group. SPRFMO IV, Noumea, New Caledonia, 4-7 Sep 2007. South Pacific Regional Fishery Management Organisation, Wellington

UNGA (United Nations General Assembly) (2007) Resolution 61/105. Sustainable fisheries, including through the 1995 Agreement for the Implementation of the Provisions of the United Nations Convention on the Law of the Sea of 10 
December 1982 relating to the Conservation and Management of Straddling Fish Stocks and Highly Migratory Fish Stocks, and related instruments. UNGA A/RES/61/105, available at www.un.org/Depts/los/general_assembly/ general_assembly_resolutions.htm

Van Gaever S, Vanreusel A, Hughes JA, Bett B, Kiriakoulakis $\mathrm{K}$ (2004) The macro- and micro-scale patchiness of meiobenthos associated with the Darwin Mounds (northeast Atlantic). J Mar Biol Assoc UK 84:547-556

Vierros M, Cresswell I, Escobar Briones E, Rice J, Ardron J (Eds) (2008) Global Open Oceans and Deep-sea habitats

Submitted: February 27, 2009; Accepted: September 4, 2009
(GOODs) bioregional classification, p 82

Watling L (2007) A review of the genus Iridogorgia (Octocorallia: Chrysogorgiidae) and its relatives, chiefly from the North Atlantic Ocean. J Mar Biol Assoc UK 87: 393-402

Williams A, Bax NJ, Kloser RJ, Althaus F, Barker B, Keith G (2009) Australia's deep-water reserve network: implications of false homogeneity for classifying abiotic surrogates of biodiversity. ICES J Mar Sci 66:214-224

Zezina O (1997) Biogeography of the bathyal zone. Adv Mar Biol 32:389-426

Proofs received from author(s): November 20, 2009 